\title{
Thermal Analysis Of Transmission with Intermediate Rolling Bodies
}

\author{
A.P. Prudnikov \\ Belarusian-Russian University \\ Mogilev, Belarus \\ prudnikov_a@tut.by
}

\begin{abstract}
The paper considers the problem of calculation of thermal characteristics for transmissions with intermediate rolling bodies, as well as the selection of lubricants and the rational design of the speed reducer, taking into consideration the heat transfer in the transmission. The results of a theoretical study of friction losses between parts of a composite roller and the main elements of the transmission with intermediate rolling bodies are given. The heat balance equation and formulas allowing us to determine the power rating on the output shaft of the transmission and the average temperature of the speed reducer casing are obtained. The adequacy of the obtained equations is confirmed experimentally on the bench for testing and determining the efficiency of the speed reducer. The thermal analysis of the transmission with intermediate rolling bodies by the finite element method allows us to determine the appropriate type of lubricant and the design of the speed reducer. The paper provides some recommendations for the calculation of the geometrical parameters of the output shaft and the use of transmissions with intermediate rolling bodies which can help prevent overheating and improper transmission operation.
\end{abstract}

Keywords- mechanical power transmission, intermediate rolling bodies, composite roller, thermal analysis, efficiency, finite element method

\section{INTRODUCTION}

Transmissions with intermediate rolling bodies have found application in compact gear mechanisms (mechatronic modules and robots) [1] and tools (spanners, winches, clamping devices). Advantages of the transmission are small overall dimensions and mass, multiple paths for load transfer, manufacturability. The main disadvantage of the transmissions with intermediate rolling bodies is their low efficiency, which explains their limited application [2].

The principle of operation of the transmission with intermediate rolling bodies can be illustrated by means of the model of the interaction of rolling bodies with the main contact elements (flat pattern view), presented in Fig. 1.

When the element (the drive shaft) rotates with the closed one-period raceway (1) on it, the rolling bodies (4) move along the grooves on the output shaft (2) and along the closed stationary multi-period raceway (3). On the flat plane the raceways (1) and (3) can be represented as sine waves; their points of intersection correspond to the location of the centers of the rolling bodies (4). When the single-period sine wave (1) (the number of periods $Z_{1}=1$ ) moves relative to the fixed multi-period sine wave (3) $\left(Z_{3}=4\right)$, the distance along the $x$ axis between points of intersection (4) remains unchanged, and a slotted element (a separator), which serves as an output shaft (2), can be added to the transmission construction. In this case, a group of points of intersection of oppositely directed parts of sine waves - going up and down - and vice versa, is considered. The displacement of the curves along the $x$-axis on the flat plane corresponds to a relative rotation of the elements in the transmission, where element (3) is stationary (fixed in the casing), and the elements (1) (drive shaft) and (2) (output shaft) rotate at different angular velocities. The transmission ratio is constant (expressed as an integer); it is defined as the sum of the numbers of the periods of the periodic curves $\left(Z_{1}+Z_{3}\right)$ and does not depend on the radial dimensions of the transmission [3, p. 33].

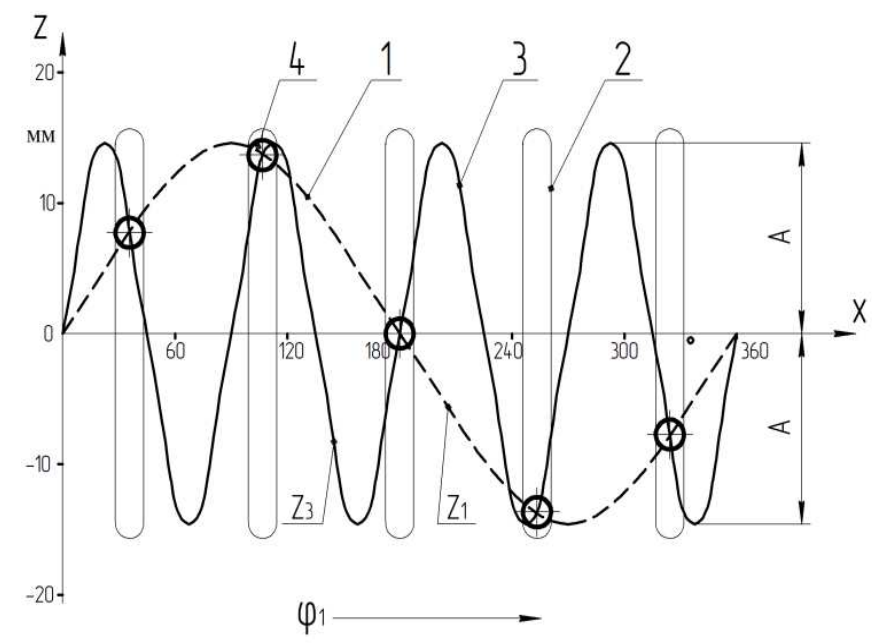

Fig. 1. Model of the interaction of intermediate rolling bodies with the main elements of the transmission (flat plane view)

The curves forming the raceways are represented as sine waves since they ensure the constant instantaneous transmission ratio and low dynamic loads. Besides, the labor intensity of manufacturing the cams forming the raceways is reduced. The parametric equations of the sine wave on a cylindrical surface have the following form: 


$$
x=R \cdot \cos \left(\frac{s_{t}}{R}\right) ; y=R \cdot \sin \left(\frac{s_{t}}{R}\right) ; z=A \cdot \sin \left(\frac{Z \cdot s_{t}}{R}\right),(1)
$$

where $R$ is the radius of the surface on which the sine wave lies, $\mathrm{m} ; s_{t}$ is the parameter used to obtain a closed raceway (it varies from 0 to $2 \cdot \pi \cdot R), \mathrm{m} ; A$ is the amplitude of the sine wave, $\mathrm{m} ; Z$ is the number of periods of the sine wave [4, p. 122].

One of the advantages of transmissions with intermediate rolling bodies is their small overall dimensions. However, since power losses in transmissions resulting from friction and converted into heat are significant, the heat transfer from the speed reducer to the environment is hampered by the small cooling surface area. The combination of small overall dimensions and low efficiency of the transmission leads to its considerable heating, which can cause a change in the gaps in the adjacent parts, which results in wedging of the rolling bodies and the improper transmission operation.

Thus, it becomes necessary to find the equations for performing thermal calculation for the transmission with intermediate rolling bodies, the selection of the type of lubricant and the rational design of the speed reducer.

\section{FINDING The HeAt BALANCE EQUATION}

In the transmissions under consideration, the force is transferred between three elements (drive shaft, output shaft and stationary element) by means of intermediate rolling bodies which are made in the form of composite rollers in order to increase the efficiency and the load capacity of the transmission. The main sources of power loss due to friction and, accordingly, heat generation are interactions of the composite roller with the main elements of the transmission and the parts of the composite roller with each other. The losses in bearings are insignificant and can be neglected.

Knowing the forces exerted on the composite roller by the transmission elements [5], it is possible to determine the friction arising in the area of interaction of composite rollers with transmission elements, as well as when the parts of the composite roller act on each other:

$$
F_{i t p}=N_{i} \cdot \frac{\delta_{\kappa}}{r} ; F_{i 1 t p}=N_{i} \cdot \delta_{c \kappa}
$$

where $N_{i}$ is the force exerted on the part of the composite roller by the corresponding element (see Fig. 2), $\mathrm{N} ; \delta_{\kappa}$ is the coefficient of friction, $\mathrm{m} ; r$ is the radius of the part of the composite roller in contact with the corresponding element of the transmission, $\mathrm{m} ; \delta_{c \kappa}$ is the coefficient of sliding friction.

The velocities of the parts of the composite roller relative to the transmission elements and the angular velocities of rotation of the parts of the composite roller are determined in [6]. The sliding velocities resulting from the interaction of the parts of the composite roller with each other are determined according to the formulas:

$$
v_{21}=r \cdot\left(\omega_{41}+\omega_{42}\right) ; v_{31}=r \cdot\left(\omega_{41}-\omega_{43}\right)
$$

where $r$ is the radius of the cylinder on which the parts of the composite roller are placed (base element), $\mathrm{m} ; \omega_{4 i}$ is the angular velocity of the corresponding part of the composite roller (see Fig. 2), rad/s.
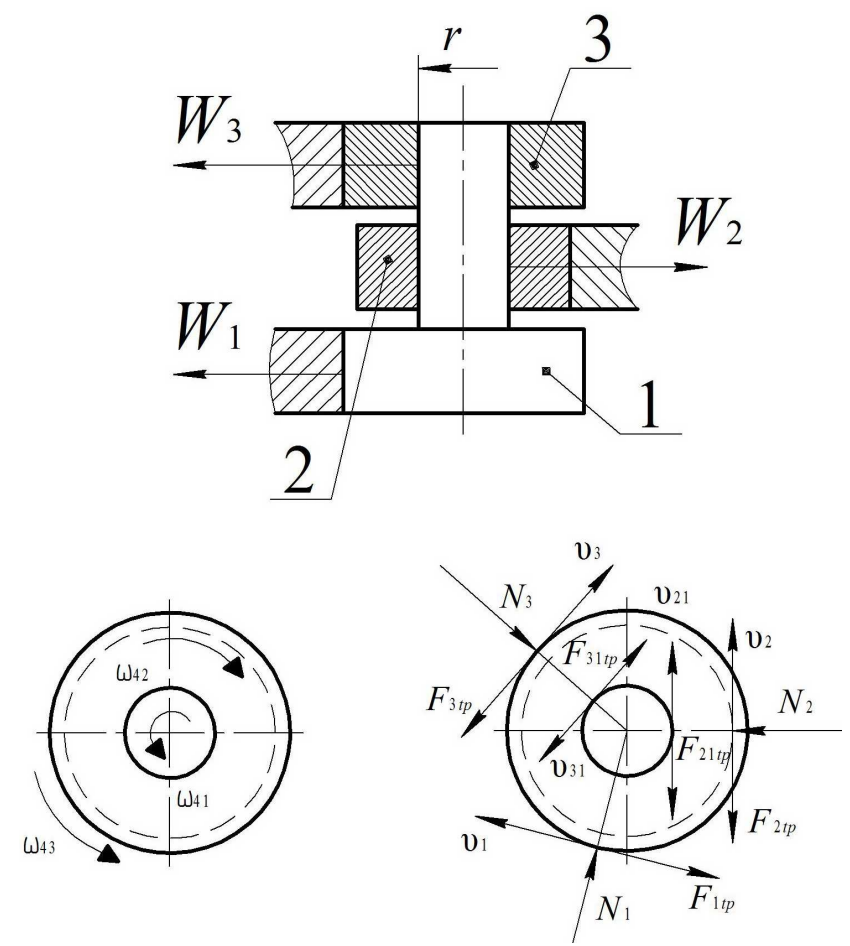

Fig. 2. Schematics of forces and velocities acting in the composite roller: $1-$ the element interacting with the drive shaft; 2 - the element interacting with the output shaft; 3 - the element interacting with a stationary element

The power losses for each component of the composite roller are determined by the formula:

$$
W_{i}=N_{i} \cdot\left(v_{i 1} \cdot \delta_{c \kappa}+v_{i} \cdot \delta_{\kappa}\right)
$$

where $v_{i 1}$ is the sliding velocity when the corresponding part of the composite roller interacts with the element on which the remaining parts of the composite roller are placed, $\mathrm{m} / \mathrm{s} ; v_{i}$ is the velocity of the part of the composite roller relative to the corresponding element (drive shaft, output shaft or stationary element), $\mathrm{m} / \mathrm{s}$.

Thus, we can determine the total power loss in the transmission:

$$
W_{\Sigma}=\left(W_{1}+W_{2}+W_{3}\right) \cdot n_{k}=P_{1} \cdot(1-\eta)
$$

where $n_{k}$ is the average number of composite rollers transferring the load [7, p. 40]; $P_{1}$ is the power on the drive shaft, $W ; \eta$ is the transmission efficiency. 
In order to ensure a normal temperature regime, the amount of heat $Q$ generated in the transmission must be less than the amount of heat $Q_{0}$ transferred from the transmission casing to the environment. Consequently, the aim of calculation is to verify whether the condition $Q<Q_{0}$ is fulfilled.

Let us write the heat balance equation for the transmission with intermediate rolling bodies as follows [8, p. 225]:

$$
W_{\Sigma} \leq K \cdot A \cdot\left(t_{1}-t_{0}\right),
$$

where $K$ is the heat transfer coefficient, $\mathrm{W} /\left(\mathrm{m}^{2} \cdot{ }^{\circ} \mathrm{C}\right) ; A$ is the cooling surface area, $\mathrm{m}^{2} ; t_{1}$ is the speed reducer temperature, ${ }^{\circ} \mathrm{C} ; t_{0}$ is the ambient temperature, ${ }^{\circ} \mathrm{C}$.

On the basis of the equation obtained, it is possible to determine the power rating on the output shaft (based on the maximum allowable temperature of the lubricant used in the transmission, graphite grease):

$$
P_{2}=\frac{80 \cdot K \cdot A \cdot \eta}{1-\eta}
$$

For the steady-state operation mode of the transmission operation, it is possible to determine the average temperature of the speed reducer casing taking into account the thermal capacity of the material of its parts:

$$
t_{1}=\frac{W_{\Sigma}+K \cdot A \cdot t_{0}+c \cdot m \cdot t_{0}}{c \cdot m+K \cdot A}
$$

where $c$ is the specific heat, $\mathrm{W} /\left(\mathrm{kg} \cdot{ }^{\circ} \mathrm{C}\right) ; m$ is the mass of the speed reducer, $\mathrm{kg}$.

\section{THE RESULTS}

To check the adequacy of the results obtained, experimental studies were carried out, during which a speed reducer with transmission ratio of 5 and a casing with diameter of $65 \mathrm{~mm}$ was loaded on the bench for measuring the efficiency (see Fig. 3). The transmission parts are made of steel (41Cr4).

When performing the tests, the following experiment parameters were set: the drive shaft speed of $n_{1}=10001 / \mathrm{min}$, the torque on the output shaft of $80 \mathrm{Nm}$. Upon reaching the steady-state operation mode and thermal equilibrium of the system, the temperature of the speed reducer casing was measured (see Fig. 4).

During the experiment, the speed reducer efficiency was found to be 0.82 and the temperature of the speed reducer casing in the element under test was $71^{\circ} \mathrm{C}$.

To analyze the transfer of heat in the transmission with intermediate rolling bodies and to explain the selection of the type of lubricant and the rational design of the speed reducer, the finite element method was used in the ANSYS software package [9]. In this case, the following initial data were set: the parameters of the speed reducer tested on the test bench; convection from the speed reducer casing; heat fluxes due to friction, which were calculated according to the formula (4).

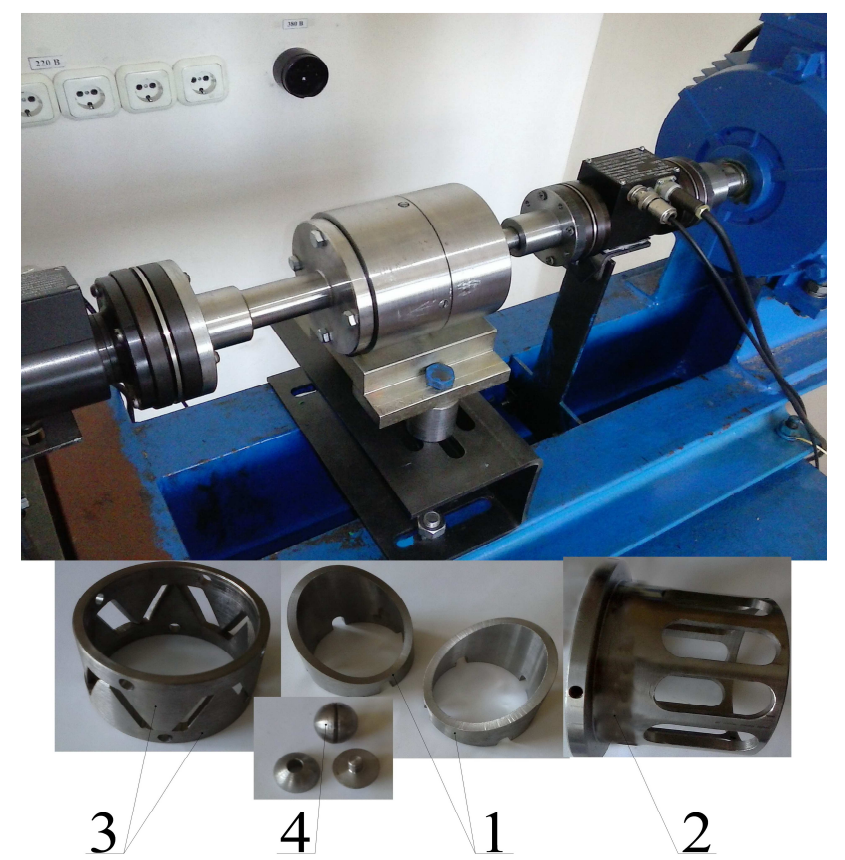

Fig. 3. Speed reducer under test: 1 - single-period face cams forming the drive element; 2 - output shaft with grooves; 3 - multi-period face cams forming a stationary element; 4 - composite rollers
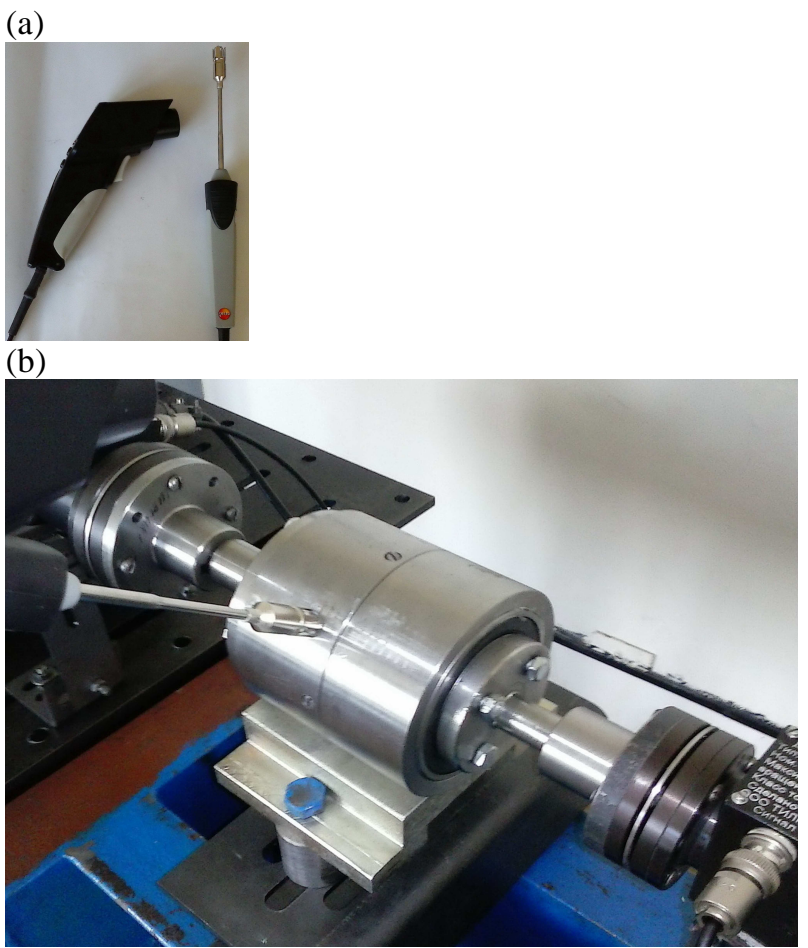

Fig. 4. Speed reducer casing temperature measurement: (a) a pyrometer with contact probe (Testo 830-T2 model); (b) measurement of the speed reducer casing temperature on the test bench 
Fig. 5 shows the thermal analysis of the transmission when using grease (graphite grease) (see Fig. 5, a) and liquid lubricant (see Fig. 5, b)

(a)
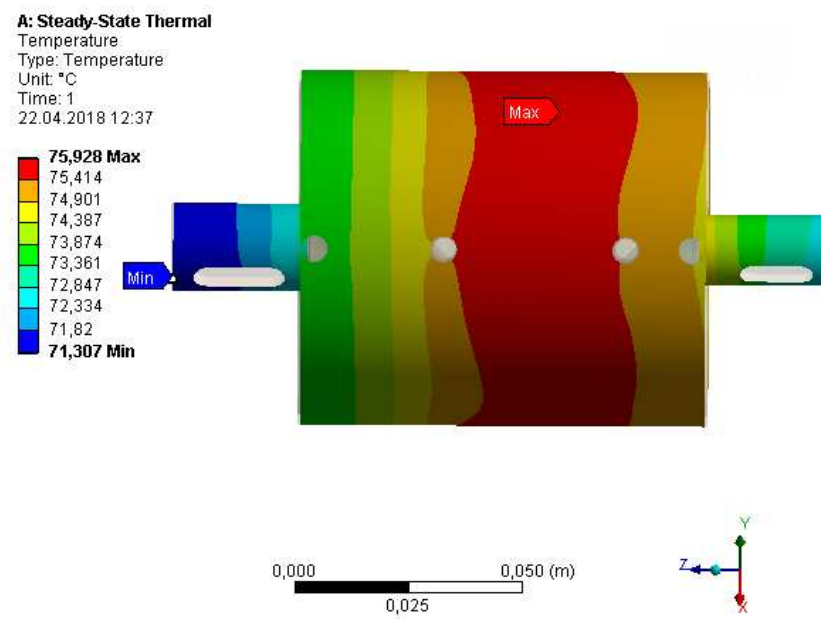

(b)

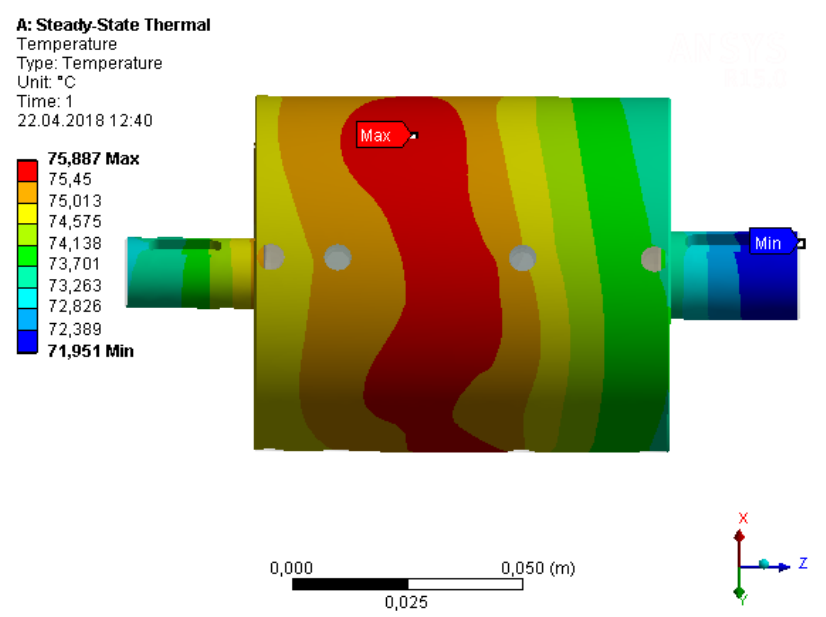

Fig. 5. Thermal analysis of the speed reducer with different types of lubricants: (a) grease (a mixture of graphite and oil); (b) liquid lubricant

If we compare the two types of lubricants used, we can see that the difference is insignificant. The reason for this is that due to the compact design of the speed reducer its parts are in contact with each other and the transmission casing and, accordingly, the heat is transferred directly to the casing, i.e. fluid does not act as thermal storage.

It was also found that the transfer of heat in the transmission with intermediate rolling bodies is influenced by gaps between an output shaft and other elements (drive and stationary) of the reducer. So if there is a gap between adjacent parts, the heat will be flowing from one element to another through intermediate rolling bodies (composite rollers).
Fig. 6 shows the thermal analysis of the transmission when the output shaft is mounted without gaps (see Fig. 6, a) and the output shaft is mounted with gaps (see Fig. 6, b).

(a)

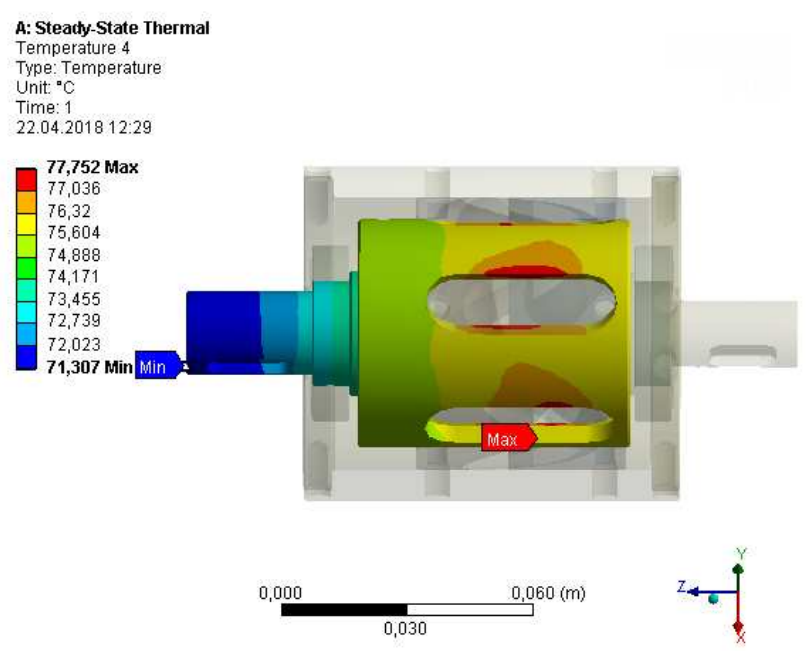

(b)

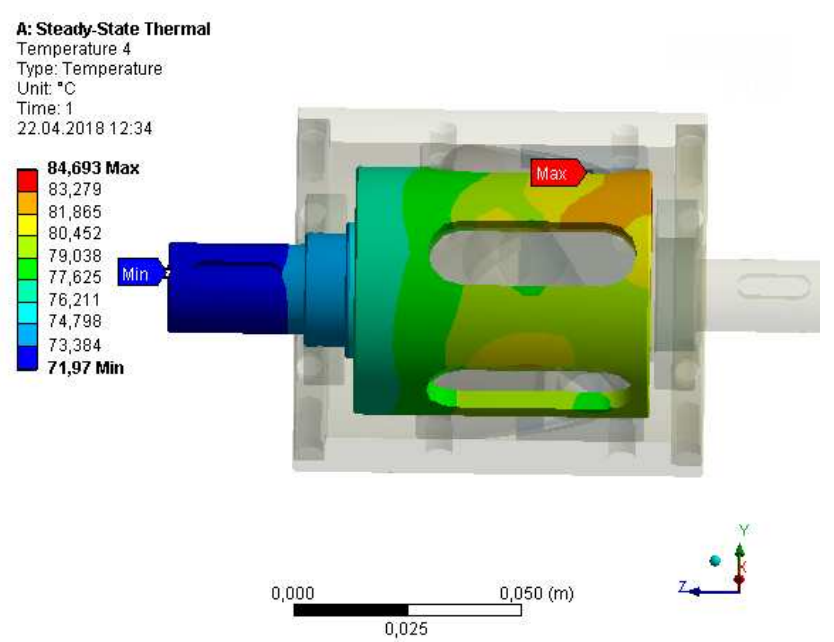

Fig. 6. Thermal analysis of the speed reducer depending on the presence of gaps between the output shaft and other elements (drive and stationary): (a) output shaft is mounted without gaps; (b) output shaft is mounted with gaps

\section{CONCLUSION}

In the course of the research, an analysis of the power losses for each part of the composite roller was performed. The heat balance equation was obtained, which allows us to determine the power rating on the output shaft of the transmission and the average temperature of the speed reducer casing. The discrepancy between the results of the calculation determined experimentally and analytically on the basis of the formula (8) is $4.3 \%$, which confirms the adequacy of the equations obtained. 
The studies conducted by means of the finite element method have shown that it is advisable to use grease lubrication for the transmission with intermediate rolling bodies from the point of view of heat balance, since it can perform its functions at higher temperatures than liquid lubricant and provides the maximum possible contact area of the stationary element with casing. The output shaft should be installed without significant gaps with the drive and stationary elements, and taking into account the fact that the output shaft is the element that undergoes the greatest heating, in the process of its manufacture the diameters of the outer and inner cylindrical surfaces must be changed by the amount of expansion of metal when heated. The magnitude of the temperature expansion of metal can be calculated according to the known formula: $\Delta h=h \cdot \alpha \cdot\left(t_{2}-t_{0}\right)$, where $h$ is the thickness of the wall of the sleeve of the output shaft, mm; $\alpha$ is the linear expansion coefficient, ${ }^{\circ} 1 / \mathrm{C}[10, \mathrm{p} .585] ; t_{2}$ is the average temperature of the output shaft, ${ }^{\circ} \mathrm{C}$.

Accordingly, the diameters of the output shaft must be as follows: outer diameter $D_{2}-\Delta h$, inner diameter $d_{2}+\Delta h$, where $D_{2}, d_{2}$ are nominal diameters of the outer and inner cylindrical surfaces of the output shaft, respectively, $\mathrm{mm}$.

To avoid overheating of the transmissions with intermediate rolling bodies, it is preferably to use them in drives operating in discontinuous mode for low power transmission. The range of power to be transmitted can be expanded by increasing the area of the heat dissipating surface area of the speed reducer (due to the ribs) or by blowing air over the casing, which increases the heat transfer coefficient by $50-100 \%$.

\section{References}

[1] W.K. Nam, J.W. Shin, S.H. Oh. "Design of thin plate-type speed reducers using balls for robots". Journal of Mechanical Science and Technology. No. 27, pp.519-524, 2013.

[2] M.E. Lustenkov. "Determination of the efficiency of transmissions with composite intermediate rolling bodies". Izvestiya vysshikh uchebnykh zavedeniy. Mashinostroenie Publ., 2014, no. 6 (651), pp. 9 - 14 (in Russ.).

[3] M.E. Lustenkov, D.M. Makarevich. "Planetarnye sharikovye peredachi tsilindricheskogo tipa" [Planetary ball gears of cylindrical type]. Mogilev, Belarusian-Russian University Publ., 2005, 123 p.

[4] M.E. Lustenkov. "Peredachi s promezhutochnymi telami kacheniya: opredelenie i minimizatsiya poter' moshchnosti tipa" [Transmissions with intermediate rolling elements: determination and minimization of power losses]. Mogilev, Belarusian-Russian University Publ., 2010, $274 \mathrm{p}$.

[5] A.P. Prudnikov. "Strength analysis of transmission with intermediate rolling bodies". Vestnik Belorussko-Rossiyskogo universiteta, 2016, no. 4 (53), pp. 56 - 66 (in Russ.).

[6] A.P. Prudnikov, M.E. Lustenkov. "Kinematic analysis of planetary gears with composite roller satellites". Vestnik Belorussko-Rossiyskogo universiteta, 2010, no. 4(29), pp. 90 - 97 (in Russ.).

[7] M.F. Pashkevich, V.M. Pashkevich, A.M. Pashkevich, S.V. Chertkov. "Planetarnye kulachkovo-plunzhernye peredachi. Proektirovanie, kontrol' i diagnostika" [Planetary cam-plunger gears. Design, monitoring and diagnostics]. Mogilev, Belarusian-Russian University Publ., 2003, $221 \mathrm{p}$.

[8] M.N. Ivanov, V.A. Finogenov. "Detali mashin: uchebnik dlya mashinostroitel'nykh spetsial'nostey vuzov" [Machine parts: a textbook for engineering specialties of universities]. Moscow, Abris Publ., 2013, $408 \mathrm{p}$.

[9] Tadeusz Stolarski, Y. Nakasone, S. Yoshimoto. "Engineering Analysis with ANSYS Software, 2nd Edition". Butterworth-Heinemann, 2018, $562 \mathrm{p}$.

[10] A. S. Zubchenko et al. "Marochnik staley i splavov" [Grade guide of steels and alloys]. Moscow, Mashinostroenie Publ., 2003, 784 p. 